\title{
Cervical intradural extramedullary cavernous malformation as a rare cause of subarachnoid hemorrhage without spinal dysfunction: illustrative case
}

\author{
Franziska Frank, MD, ${ }^{1}$ Jens Maybaum, MD, ${ }^{2}$ Clara Frydrychowicz, MD, ${ }^{3}$ Kristin Stoll, MD, ${ }^{4}$ Khaled Gaber, MD, ${ }^{1}$ and \\ Jürgen Meixensberger, $\mathrm{MD}^{1}$ \\ ${ }^{1}$ Department of Neurosurgery, ${ }^{2}$ Institute for Neuroradiology, ${ }^{3}$ Institute for Neuropathology, and ${ }^{4}$ Department of Neurology, University Hospital Leipzig, Leipzig, Germany
}

BACKGROUND Intradural extramedullary cavernoma is a very rare lesion of the spinal cord, especially of the cervical spine. Its clinical presentation can vary with symptoms of sensory or motor deficits and even with symptoms of subarachnoid hemorrhage (SAH).

OBSERVATIONS The authors present a case of a 45-year-old man with SAH with prolonged neck pain and increasing headache confirmed by lumbar puncture. Head computed tomography revealed only discrete blood deposits in the right frontal and biparietal lobes. The finding of pan-cerebral angiography was negative for the cause of bleeding. Spinal magnetic resonance imaging revealed an intradural extramedullary mass lesion at cervical level C5-6. The finding of subsequent cervical angiography was negative. The diagnosis of a cavernous malformation was confirmed histopathologically after surgery. The cavernoma was completely removed, and full recovery of the initial symptoms was achieved.

LESSONS Spinal lesions should be considered in the diagnostic work-up for SAH with excluded origin of bleeding in cranial neuroimaging. An intradural extramedullary cavernous malformation is an extremely rare entity in the differential diagnosis of $\mathrm{SAH}$, and surgical resection is the treatment of choice to prevent further bleeding and neurological deficits.

https://thejns.org/doi/abs/10.3171/CASE21463

KEYWORDS intradural extramedullary cavernous malformation; spinal cavernoma; subarachnoid hemorrhage

A cavernous malformation consists of dilated, thin-walled sinusoids lined with a single endothelial layer. Intervening glial or neural tissue is missing within the lesions, but they show a clear demarcation from the surrounding tissue with a ring of hemosiderin and an organizing thrombus in various stages in the center with a histological appearance of a mulberry. ${ }^{1}$ Lacking subendothelial support and rare intact tight junctions between endothelial cells have been discussed as contributing to the growth with recurrent, discrete bleeding. ${ }^{2}$ On magnetic resonance imaging (MRI) scans, the presentation of these lesions varies with mostly mixed signal intensity in T1- and T2-weighted images and variable slight contrast enhancement according to different states of the organizing hemorrhage and hemosiderin deposits. $^{3}$

The actual incidence of spinal cavernomas is unknown due to their clinical mostly unapparent existence, but they represent approximately $5 \%-16 \%$ of all spinal vascular malformations, with the majority originating in the vertebrae with occasional extension to the extradural space. Only $3 \%$ are found to be intramedullary, and even less common are intradural extramedullary localizations. ${ }^{4,5}$

In 1903, the first case of an intradural extramedullary spinal cavernoma was reported by Hadlich as an incidental autopsy finding. ${ }^{6}$ In 1973, the first surgically treated cervical intradural extramedullary cavernoma was described by Ortner. ${ }^{7}$ Due to the variety of clinical presentations and their uncommonness, the diagnostic work-up of these lesions can be challenging.

We report a case of a cervical intradural extramedullary cavernous malformation in a patient who presented with prolonged neck pain and increasing headache mimicking subarachnoid hemorrhage (SAH); further symptoms or signs of spinal dysfunction were missing. In addition, we present the diagnostic work-up needed to avoid

ABBREVIATIONS CT = computed tomography; MRI = magnetic resonance imaging; SAH = subarachnoid hemorrhage.

INCLUDE WHEN CITING Published March 7, 2022; DOI: 10.3171/CASE21463.

SUBMITTED August 13, 2021. ACCEPTED October 1, 2021.

(c) 2022 The authors, CC BY-NC-ND 4.0 (http://creativecommons.org/licenses/by-nc-nd/4.0/). 
recurrent bleeding and neurological deficits, as well as review the available literature.

\section{Illustrative Case}

A 45-year-old man presented to the orthopedic outpatient clinic with a sudden onset of neck pain radiating into both arms but with no further sensorimotor deficit. Similar symptoms were known but not of the same intensity. Previous analgesic medication did not improve the symptoms. The clinical orthopedic and clinical neurological examinations were without any pathological results. An acute infection could be excluded with only slightly increased C-reactive protein in the laboratory examination. The radiographic examination of the cervical spine showed, besides a steep position, no further pathological findings. The patient was discharged home with a diagnosis of a cervical syndrome and recommendation for conservative therapy.

Only 3 days later, the patient presented again with progressive holocephalic headache refractory to analgesic medication with an intensity up to $9 / 10$ on the numeric rating scale. Onset with a thunderclap headache was denied. Only slight symptoms of dizziness, an increased sensitivity to pressure over both eyeballs, and nausea with one-time vomiting were reported. Unconsciousness or altered mental condition was not observed at any time. The finding of the clinical neurological examination was negative for any further deficit aside from neck rigidity.

In the patient's medical history, no previous illnesses were known apart from a positive smoking history ( 25 pack-years); his travel history was negative. Both $\mathrm{SAH}$ and meningitis were considered in the differential diagnosis.

The initial cranial computed tomography (CT) scan showed very discrete subarachnoid blood deposits on the right frontal and biparietal lobes. Lumbar puncture revealed bloody cerebrospinal fluid with a positive three-glass sample. With the diagnosis of SAH with reactive inflammation, the patient was closely monitored, and additional diagnostic work-up was initiated. In pan-angiography of the cerebral vessels, no source of bleeding could be detected. Further total spinal MRI scans showed a right anterolaterally located intradural extramedullary mass lesion measuring $1 \times 3 \mathrm{~cm}$ in size at the cervical level of $\mathrm{C} 5-6$. The lesion was mixed hyperintense and hypointense on T2-weighted images and isointense on T1-weighted images with slightly heterogeneous contrast enhancement and intramedullary edema, raising suspicion for hemorrhage or a cavernous malformation (Fig. 1). Cervical angiography excluded arteriovenous malformation and other pathological vascular supply.

Microsurgical resection of the mass lesion with a C5-6 laminoplasty was performed under a microscope. On the right side, an old hemorrhage was visible in the intradural extramedullary region with a central part adherent to nerve root $\mathrm{C} 6$ and a displacement of the spinal cord to the left side. The lesion was totally removed with preservation of the rootlets (Fig. 2).

Histological examination showed a conglomeration of irregularly dilated sinusoidal loops with a single cell layer and components of recent and previous bleedings. In immunohistochemistry, staining for CD31 was strongly positive (Fig. 2). The diagnosis of cavernous malformation was confirmed.

The patient's postoperative course was uneventful, and no further sensorimotor deficit with decreasing headache was reported. The total removal of the mass lesion was confirmed with postoperative cervical MRI.

\section{Discussion}

\section{Observations}

Approximately 60 cases of intradural extramedullary cavernous malformations have been reported, mostly located at the thoracolumbar
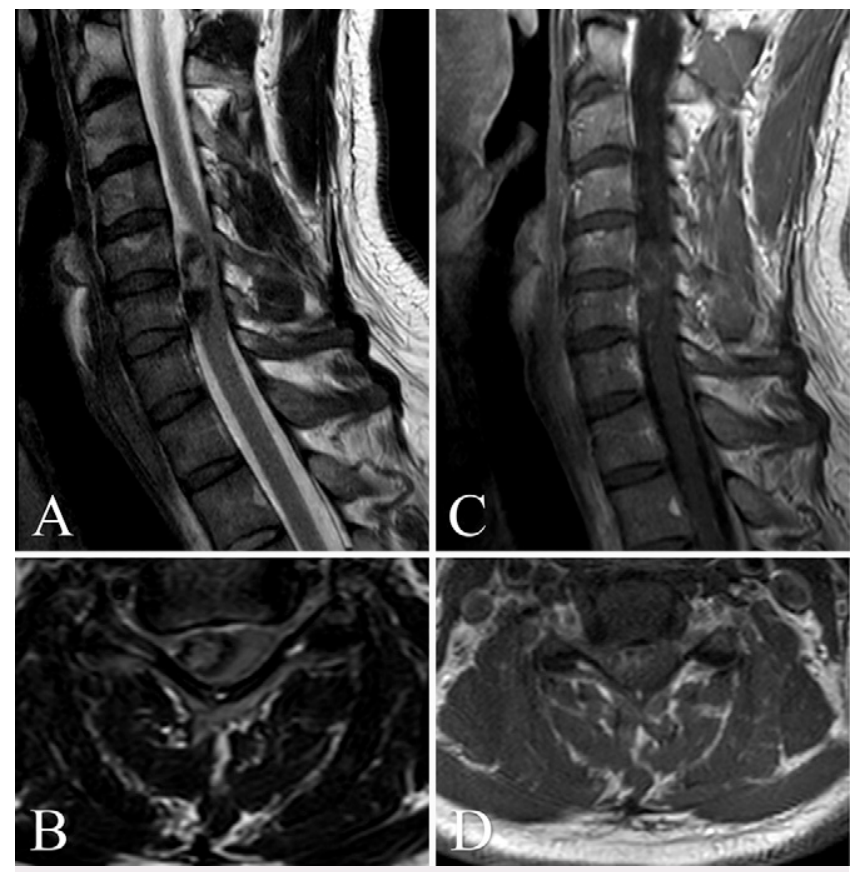

FIG. 1. Right anterolateral intradural extramedullary mass lesion located at cervical level C5-6 with craniocentral popcorn-like portions and immediately inferior circumscribed hemorrhage on sagittal $(\mathbf{A})$ and axial (B) T2-weighted imaging. Central hyperintense signal surrounded by hypointense hemosiderin ring $(B)$. Discrete inhomogeneous contrast enhancement in the central parts of mass lesion on isointense sagittal (C) and axial (D) T1-weighted imaging.

level and with a predominance of male patients. ${ }^{8-12}$ Due to compression of the nerve root or spinal cord, the lesions become clinically evident with localized back pain, radiculopathy, and spinal dysfunction
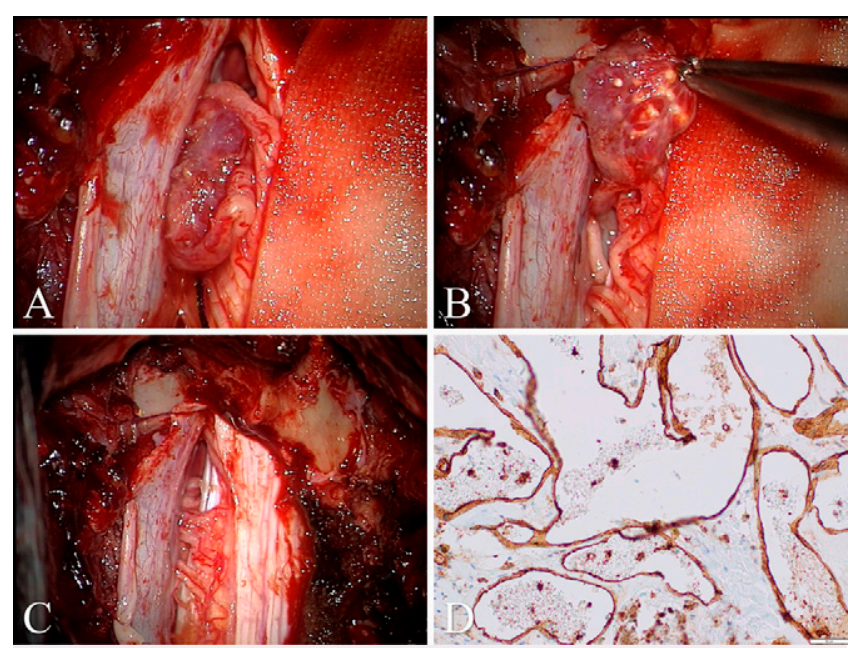

FIG. 2. Intraoperative photographs after opening of dura of a bluish, mulberry-shaped lesion ventrolateral to spinal cord adherend to nerve $\operatorname{root}(\mathbf{A}, \mathbf{B})$. Complete removal under a microscope preserving the rootlets (C). CD31-positive immunohistochemical staining of large dilated vascular loops lying back to back to each other without intervening tissue (D). 
(sensorimotor deficit, sphincter dysfunction) and in some cases even with SAH according to recurrent bleeding., 83

Spinal cavernoma associated with $\mathrm{SAH}$ has been described at both the thoracic and lumbar levels. 9,10,14,15 Interestingly, two cases associated with hydrocephalus ${ }^{16,17}$ and two further cases associated with cerebral hemosiderosis due to chronic subarachnoid bleeding have been described. ${ }^{18,19}$ According to available data, only 10 cases, including our case, have been described as being located at the cervical level (Table 1). The age of the patients ranged between the second and seventh decades of life (age range, 22-76 years) with a mean of 51 years, and cases predominantly occur in men (male/female ratio, 7:3). When described precisely during a surgical procedure, cavernomas were mostly adherent to nerve roots, and a total resection was possible in all cases with a complete recovery in seven cases (Table 1). According to severe neurological disturbance with Brown-Sequard syndrome, only an incomplete recovery was possible in two cases. ${ }^{4,20}$ Hence, the severity of symptoms seem to be significantly related to the clinical outcome.

Three cases, including ours, presented with symptoms suspicious for SAH according to positive results of lumbar puncture or even a CT scan. ${ }^{21,22}$ Similar to our case, despite a short transient presentation with radiating pain that was referred to as "cervical syndrome," diagnostic work-up for a cranial source of bleeding was primarily performed, in contrast to preferred spinal MRI scans, due to spinal dysfunction with sensorimotor deficits or permanent radiating pain. ${ }^{12,20,23}$ In fact, SAH could be present in even more cases with extended pain, as described intraoperatively by Rachinger et al., but lumbar puncture was not performed regularly. ${ }^{12}$

As analyzed before, in approximately $15 \%-20 \%$ of nontraumatic $\mathrm{SAH}$ cases, angiography fails to identify the origin of bleeding. ${ }^{24,25}$ Additional work-up for these patients remains unclear. For an additional cervical MRI in nontraumatic SAH with a negative pan-angiography finding, a pooled estimate for the diagnostic yield of spinal MRI was reported to be $1.3 \%$ and could not be routinely recommended in the absence of clinical and neurological findings. ${ }^{24,25}$ However, with suggestive symptoms or recurrent bleeding, spinal MRI should be considered to prevent further permanent neurological deficits or even worse deficits. The annual rate of recurrent bleeding was reported to be $1.7 \%$ in conservatively treated patients with spinal cord cavernous malformations, especially in those with sensorimotor neurological deficits; asymptomatic patients or those with minor symptoms could be treated conservatively. ${ }^{26}$

The literature is heterogeneous regarding the treatment of patients with angiographically negative $\mathrm{SAH}$, and detailed instructions are lacking in guidelines. Nevertheless, use of enhanced MRI in patients with proven SAH without evidence of a source of bleeding is standard in clinical practice.

TABLE 1. Summary of published cases of surgically treated cervical intradural extramedullary cavernoma

\begin{tabular}{|c|c|c|c|c|c|c|c|c|}
\hline Case No. & $\begin{array}{c}\text { Authors \& } \\
\text { Year }\end{array}$ & Age (yrs), Sex & Level & Origin & Symptoms & $\begin{array}{l}\text { Lumbar } \\
\text { Puncture }\end{array}$ & Surgery Extent & $\begin{array}{l}\text { Outcome } \\
\text { (recovery) }\end{array}$ \\
\hline 1 & $\begin{array}{c}\text { Ortner et al., } \\
1973^{7}\end{array}$ & $22, \mathrm{M}$ & C4-7 & ND & $\begin{array}{c}\text { SAH, } \\
\text { tetraplegia, } \\
\text { cranial nerve } \\
\text { failure }\end{array}$ & Bloody CSF & Total & $\begin{array}{c}\text { No } \\
\text { improvement }\end{array}$ \\
\hline 2 & $\begin{array}{c}\text { Acciarri et al., } \\
1992^{21}\end{array}$ & $54, F$ & C2-3 & Dura & $\mathrm{SAH}$ & Bloody CSF & Total & Complete \\
\hline 3 & $\begin{array}{c}\text { Harrison } \\
\text { et al., } 1995^{4}\end{array}$ & $37, \mathrm{M}$ & CCJ-C5 & Root & $\begin{array}{l}\text { Brown-Sequard } \\
\text { syndrome }\end{array}$ & ND & Total & Incomplete \\
\hline 4 & $\begin{array}{l}\text { Nozaki et al., } \\
2003^{23}\end{array}$ & $51, M$ & C5-6 & Root & $\begin{array}{c}\text { Shoulder pain, } \\
\text { sensorimotor } \\
\text { deficit }\end{array}$ & ND & Total & Complete \\
\hline 5 & $\begin{array}{c}\text { Park et al., } \\
2003^{22}\end{array}$ & $61, M$ & C1-2 & ND & Headache & Bloody CSF & Total & Complete \\
\hline 6 & $\begin{array}{l}\text { Rachinger } \\
\text { et al., } 2006^{12}\end{array}$ & $56, \mathrm{M}$ & C6-7 & Root & $\begin{array}{l}\text { Shoulder pain, } \\
\text { total spine } \\
\text { pain, sensory } \\
\text { deficit }\end{array}$ & ND & Total & Complete \\
\hline 7 & $\begin{array}{l}\text { Kivelev et al., } \\
2008^{20}\end{array}$ & $44, \mathrm{M}$ & C5-6 & Root & $\begin{array}{l}\text { Brown-Sequard } \\
\text { syndrome, } \\
\text { incontinence }\end{array}$ & ND & Total & Incomplete \\
\hline 8 & $\begin{array}{l}\text { Henderson } \\
\text { et al., } 2018^{11}\end{array}$ & $65, F$ & $\mathrm{C} 6$ & Root & $\begin{array}{l}\text { Radiculopathy, } \\
\text { sensory deficit }\end{array}$ & ND & Total & Complete \\
\hline 9 & $\begin{array}{l}\text { Pétillon et al., } \\
2018^{3}\end{array}$ & $76, F$ & C7-8 & Root & Neck pain & ND & Total & Complete \\
\hline 10 & Present case & $45, M$ & C5-6 & Root & $\begin{array}{l}\text { SAH, transient } \\
\text { radiculopathy }\end{array}$ & Bloody CSF & Total & Complete \\
\hline
\end{tabular}

$\mathrm{CCJ}=$ craniocervical junction; $\mathrm{CSF}=$ cerebrospinal fluid; $\mathrm{ND}=$ not described. 


\section{Lessons}

Due to an early presentation with progressive neck pain and headache, the diagnosis could be made early with a positive outcome and no further sensorimotor deficits in the patient. However, the diagnostic work-up can be challenging because of the variety of clinical presentations. Cervical intradural extramedullary cavernous malformation is a very rare entity among spinal lesions and must be considered as a potential cause of SAH without spinal dysfunction. An extended diagnostic work-up is mandatory to prevent recurrent bleeding and permanent neurological deficits. Surgical removal is the therapy of choice for symptomatic intradural extramedullary cavernous malformations.

\section{Acknowledgments}

We acknowledge support from Leipzig University for open access publishing.

\section{References}

1. Clatterbuck RE, Eberhart CG, Crain BJ, Rigamonti D. Ultrastructural and immunocytochemical evidence that an incompetent blood-brain barrier is related to the pathophysiology of cavernous malformations. J Neurol Neurosurg Psychiatry. 2001;71(2):188-192.

2. Wong JH, Awad IA, Kim JH. Ultrastructural pathological features of cerebrovascular malformations: a preliminary report. Neurosurgery. 2000;46(6):1454-1459.

3. Pétillon P, Wilms G, Raftopoulos C, Duprez T. Spinal intradural extramedullary cavernous hemangioma. Neuroradiology. 2018;60(10):1085-1087.

4. Harrison MJ, Eisenberg MB, Ullman JS, Oppenheim JS, Camins MB, Post KD. Symptomatic cavernous malformations affecting the spine and spinal cord. Neurosurgery. 1995;37(2):195-205.

5. Jellinger K. Vascular malformations of the central nervous system: a morphological overview. Neurosurg Rev. 1986;9(3):177-216.

6. Hadlich R. Ein Fall von Tumor Cavernosus des Rueckenmarks mit besonderer Beruecksichtigung der neueren Theorien ueber die Genesis des Kavernom. Virchows Arch. 1903;172:429-441.

7. Ortner WD, Kubin H, Pillz P. Ein zervikales kavernöses angiom. Fortschr Röntgenstr. 1973;118(4):475-476.

8. Golnari P, Ansari SA, Shaibani A, et al. Intradural extramedullary cavernous malformation with extensive superficial siderosis of the neuraxis: case report and review of literature. Surg Neurol Int. 2017;8:109.

9. Tao CY, He M, Zhang YK, You C. Upper thoracic intradural-extramedullary cavernous malformation presenting as subarachnoid hemorrhage without spinal dysfunction: a case report and review of the literature. Br J Neurosurg. 2014;28(6):808-810.

10. Vicenty JC, Fernandez-de Thomas RJ, Estronza S, Mayol-Del Valle MA, Pastrana EA. Cavernous malformation of a thoracic spinal nerve root: case report and review of literature. Asian J Neurosurg. 2019;14(3):1033-1036.

11. Henderson F Jr, Skipper DC, Patel S. Cervical spinal root cavernoma: case report and review. Br J Neurosurg. 2018;32(4): 445-447.

12. Rachinger J, Buslei R, Engelhorn T, Doerfler A, Strauss C. Intradural-extramedullary cavernous hemangioma of the left motor root C7 - case report and update of the literature. Zentralbl Neurochir. 2006;67(3):144-148.

13. Popescu M, Titus Grigorean V, Julieta Sinescu C, et al. Cauda equina intradural extramedullary cavernous haemangioma: case report and review of the literature. Neurol Med Chir (Tokyo). 2013; 53(12):890-895.
14. Cervoni L, Celli P, Gagliardi FM. Cavernous angioma of the cauda equina: report of two cases and review of the literature. Neurosurg Rev. 1995;18(4):281-283.

15. Yang T, Wu L, Yang $C$, Deng $X, X u Y$. Cavernous angiomas of the cauda equina: clinical characteristics and surgical outcomes. Neurol Med Chir (Tokyo). 2014;54(11):914-923.

16. Ramos F Jr, de Toffol B, Aesch B, Jan M. Hydrocephalus and cavernoma of the cauda equina. Neurosurgery. 1990;27(1):139-142.

17. Makino K, Takamura H, Gotoh S, Andoh M. Cauda equina cavernous hemangioma associated with hydrocephalus - case report. Article in Japanese. No To Shinkei. 1995;47(8):783-787.

18. Jin YJ, Chung SB, Kim KJ, Kim HJ. Spinal intradural extramedullary cavernoma presenting with intracranial superficial hemosiderosis. J Korean Neurosurg Soc. 2011;49(6):377-380.

19. Katoh N, Yoshida T, Uehara T, Ito K, Hongo K, Ikeda S. Spinal intradural extramedullary cavernous angioma presenting with superficial siderosis and hydrocephalus: a case report and review of the literature. Intern Med. 2014;53(16):1863-1867.

20. Kivelev J, Ramsey CN, Dashti R, Porras M, Tyyninen O, Hernesniemi J. Cervical intradural extramedullary cavernoma presenting with isolated intramedullary hemorrhage. J Neurosurg Spine. 2008;8(1):88-91.

21. Acciarri N, Padovani R, Pozzati E, Gaist G, Manetto V. Spinal cavernous angioma: a rare cause of subarachnoid hemorrhage. Surg Neurol. 1992;37(6):453-456.

22. Park J, Chung $\mathrm{C}, \mathrm{Kim} \mathrm{H}$. Intradural-extramedullary spinal cavernous angioma as a cause of subarachnoid hemorrhage. J Korean Neurosurg Soc. 2003;34(6):174-176.

23. Nozaki K, Inomoto T, Takagi Y, Hashimoto N. Spinal intradural extramedullary cavernous angioma. Case report. J Neurosurg. 2003;99(3 suppl):316-319.

24. Sadigh G, Holder CA, Switchenko JM, Dehkharghani S, Allen JW. Is there added value in obtaining cervical spine MRI in the assessment of nontraumatic angiographically negative subarachnoid hemorrhage? A retrospective study and meta-analysis of the literature. J Neurosurg. 2018;129(3):670-676.

25. Germans MR, Coert BA, Majoie CB, et al. Yield of spinal imaging in nonaneurysmal, nonperimesencephalic subarachnoid hemorrhage. Neurology. 2015;84(13):1337-1340.

26. Kim KM, Chung CK, Huh W, et al. Clinical outcomes of conservative management of spinal cord cavernous angiomas. Acta Neurochir (Wien). 2013;155(7):1209-1214.

\section{Disclosures}

The authors report no conflict of interest concerning the materials or methods used in this study or the findings specified in this paper.

\section{Author Contributions}

Conception and design: Frank, Gaber, Meixensberger. Acquisition of data: Frank, Frydrychowicz, Stoll, Meixensberger. Analysis and interpretation of data: Frank, Maybaum, Stoll, Gaber. Drafting the article: Frank, Frydrychowicz. Critically revising the article: Frydrychowicz, Gaber, Meixensberger. Reviewed submitted version of manuscript: Frydrychowicz, Stoll, Gaber, Meixensberger. Approved the final version of the manuscript on behalf of all authors: Frank. Administrative/technical/material support: Maybaum, Frydrychowicz, Stoll, Gaber. Study supervision: Gaber.

\section{Correspondence}

Franziska Frank: University Hospital Leipzig, Leipzig, Germany. franziska.frank@medizin.uni-leipzig.de. 